\title{
Cone-beam computed tomography characterization of the intraosseous vascular canal in the lateral wall of the maxillary antrum
}

\author{
Shishir Ram Shetty ${ }^{1}$, Saad Wahby Al Bayatti ${ }^{1}$, Hesham Marei ${ }^{2}$, Raghavendra Shetty ${ }^{3}$, \\ Hossam Abdelatty Abdelmagyd ${ }^{4}$, Alexander Maniangat Luke ${ }^{3}$ \\ ${ }^{l}$ Oral Radiology, Department of Oral and Craniofacial Health Sciences, College of Dental Medicine, University of Sharjah, Sharjah, \\ ${ }^{2}$ Oral and Maxillofacial Surgery, College of Dentistry, Gulf Medical University, ${ }^{3}$ Department of Clinical Sciences, College of Dentistry, \\ Ajman University, ${ }^{4}$ Periodontics, College of Dentistry, Gulf Medical University, Ajman, United Arab Emirates
}

\begin{abstract}
J Korean Assoc Oral Maxillofac Surg 2021;47:34-39)
Objectives: The purpose of the study was to assess the occurrence, location, and dimensions of the intraosseous vascular canal in the lateral wall of the maxillary antrum using cone-beam computed tomography (CBCT).

Materials and Methods: In this retrospective study, we examined 400 CBCT scans from our archive of patients who had earlier reported to a dental teaching hospital in the United Arab Emirates. The prevalence, location, and dimensions of the lateral antral intraosseous canal (LAIC) in the maxillary antrum were evaluated by 2 examiners using standardised methods. A third examiner was consulted in cases of disagreement.

Results: The prevalence of LAIC was $62.3 \%$ (249 maxillary antra) among the study population. The mean distance between the most inferior point of the alveolar bone and the inferior border of the LAIC in the posterior maxillary region was $19.83 \pm 3.12 \mathrm{~mm}$. There was a significant difference $(P=0.05)$ between the maxillary molar and premolar regions in mean distance from the most inferior point of the alveolar bone and the inferior border of the LAIC. There was no statistically significant difference in mean distance between the most inferior point of the alveolar bone and the inferior border of the LAIC between dentulous and edentulous areas $(P=0.1)$. The G3-intrasinusal type canal less than $1 \mathrm{~mm}$ in diameter was the most common type of LAIC.

Conclusion: This study established the approximate location of the LAIC in a United Arab Emirates cohort, which will assist the oral surgeon in selecting the appropriate site for sinus lift procedures with reduced risk of surgical hemorrhage.
\end{abstract}

Key words: Maxillary sinus, Cone-beam computed tomography, Sinus floor augmentation, Hemorrhage, Alveolar bone loss [paper submitted 2020. 9. 16 / revised 2020. 11. 3 / accepted 2020. 11. 10]

\section{Introduction}

Dental implants are gaining popularity in the Middle East. According to recent surveys in the Middle East, $76 \%$ to $80 \%$ of respondents with tooth loss were willing to undergo implant therapy ${ }^{1}$. Newer surgical techniques have allowed placement of dental implants in clinical conditions

\footnotetext{
Shishir Ram Shetty

Oral Radiology, Department of Oral and Craniofacial Health Sciences, College of Dental Medicine, University of Sharjah, P.O. Box 27272 Sharjah, United Arab Emirates

TEL: +971-067435772

E-mail: shishirshettyomr@gmail.com

ORCID: https://orcid.org/0000-0002-8097-6024

(c) This is an open-access article distributed under the terms of the Creative Commons Attribution Non-Commercial License (http://creativecommons.org/ licenses/by-nc/4.0/), which permits unrestricted non-commercial use, distribution, and reproduction in any medium, provided the original work is properly cited. Copyright (C) 2021 The Korean Association of Oral and Maxillofacial Surgeons. All rights reserved.
}

which were previously contraindicated ${ }^{2}$. The lateral window technique in sinus lift surgery is sometimes associated with risk of hemorrhage as a result of inadvertent laceration of the lateral intraosseous blood vessels located in the lateral wall of the maxillary antrum ${ }^{3,4}$. Due to their intraosseous location in the lateral antral wall, these vessels have an estimated $20 \%$ chance of sustaining injury during direct sinus lift procedures ${ }^{5,6}$. Recently published studies have revealed variations in occurrence and location of the lateral antral intraosseous canals (LAIC) $)^{4,-11}$. Currently, no studies regarding the incidence and location of the lateral antral intraosseous blood vessels in the Middle Eastern population have been published. We conducted a study to evaluate the occurrence and location of lateral antral intraosseous vascular canals in a United Arab Emirates (UAE) population. 


\section{Materials and Methods}

The study was conducted between January to August 2020. Cone-beam computed tomography (CBCT) images from 200 patients (400 maxillary sinuses) at Thumbay Dental Hospital, Gulf Medical University, Ajman, UAE, were evaluated in this retrospective study. Prior to commencement of the study, ethical clearance was obtained from the Institutional Review Board of Gulf Medical University (No. INT/COD/FR/0062020), and the written informed consent was obtained from all patients. The CBCT examinations of the sino-nasal variants were performed using a ProMax 3D Mid (Planmeca, Helsinki, Finland), operated at $90 \mathrm{kVp}$ and $10 \mathrm{~mA}$ with a $9 \times 16 \mathrm{~cm}$ field of view. Assessment of CBCT scans was directly performed on a 1,920×1,080 pixel and 23-inch DELL monitor (DELL, Round Rock, TX, USA). Voxel edge length was $0.2 \mathrm{~mm}$, and slice thickness was $1 \mathrm{~mm}$. The CBCT scans of patients with a history of trauma or surgery involving the maxillofacial region or those with clinical or radiographic indication of developmental anomalies affecting the maxillofacial region were excluded from the study. The CBCT scans of subjects with first premolars located anterior to the maxillary antrum were excluded from the study, following research by Mung San Aung et al. ${ }^{4}$. The CBCT scans of the subjects were evaluated by an oral radiologist and an oral surgeon with 10 years of clinical experience. In cases of inter-observer dis-

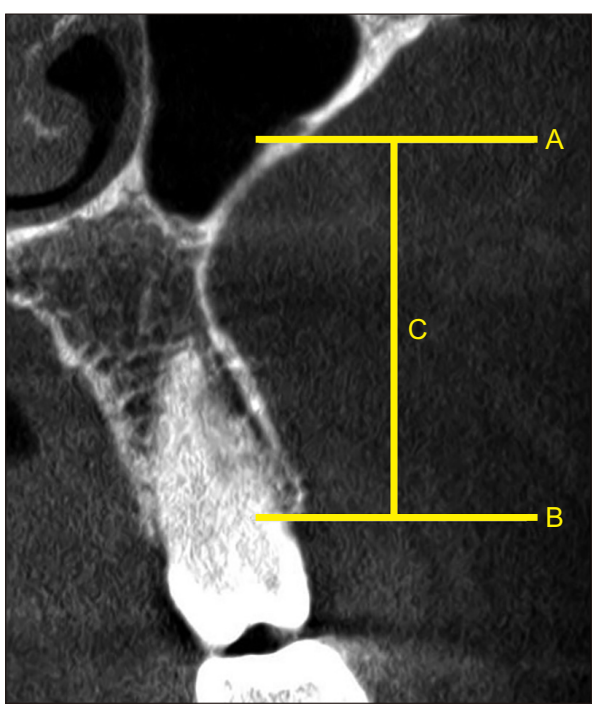

Fig. 1. Procedure followed for the measurement of lateral antral intraosseous canal (LAIC) location. Lower border of the LAIC (A), lowest point of the alveolar crest $(\mathrm{B})$ used for measurement of distance (C).

Shishir Ram Shetty et al: Cone-beam computed tomography characterization of the intraosseous vascular canal in the lateral wall of the maxillary antrum. J Korean Assoc Oral Maxillofac Surg 2021 agreement, a 3rd examiner (an oral surgeon with 10 years of clinical experience) was consulted for the final decision. To determine intra-observer variance, 50 CBCT scans (100 maxillary antra) were examined twice with one-month by the same examiners $(r=0.92)$.

The criteria used for identification and dimensional measurement of LAIC were from the study conducted by Mardinger et al. ${ }^{12}$. According to these criteria, four reference CBCT landmarks were considered for locating the position of the LAIC.(Fig. 1) The reference points were the centres of the crowns of the first premolar, second premolar, first molar, and second molar mesiodistally and bucco-lingually at the level of the alveolar crest in the axial view, with an equivalent distance from the adjacent tooth of the dentate $\operatorname{side}^{13}$. The diameters of the LAIC were divided into four categories based on the criteria employed by Mardinger et al. ${ }^{12}$ in their computed tomography (CT)-based study. To locate the reference points in the sub-sinusal edentulous maxilla (Fig. 2) and determine the horizontal dimensions of LAIC, the technique devised by Lee et al. ${ }^{13}$ was applied. The data were analysed using IBM SPSS Statistics (ver. 26; IBM, Armonk, NY, USA). A $P$-value $<0.05$ was considered statistically significant.

\section{Results}

The prevalence of LAIC was 62.3\% (249 maxillary antra)

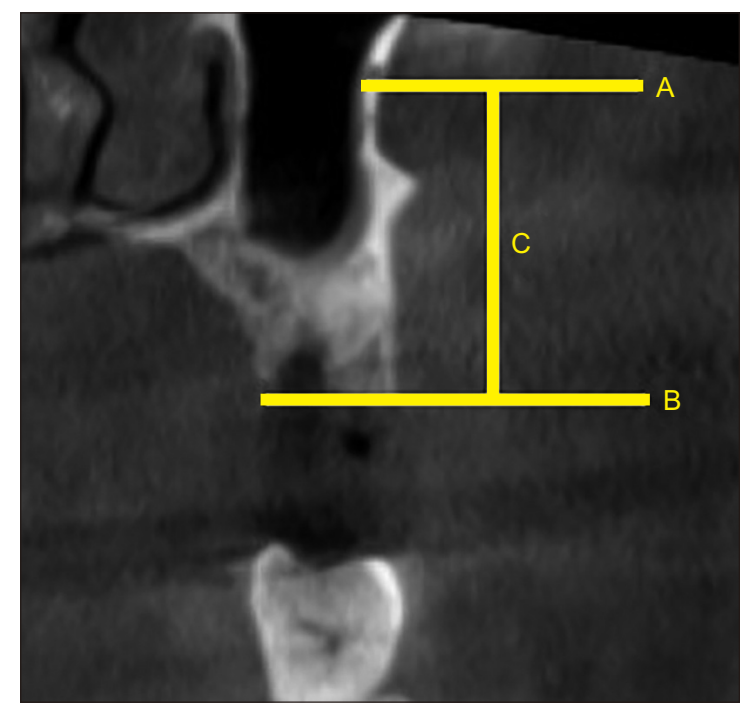

Fig. 2. Procedure followed for the measurement of lateral antral intraosseous canal (LAIC) location in edentulous patient. Lower border of the LAIC (A), lowest point of the residual alveolar ridge (B) used for measurement of distance (C).

Shishir Ram Shetty et al: Cone-beam computed tomography characterization of the intraosseous vascular canal in the lateral wall of the maxillary antrum. J Korean Assoc Oral Maxillofac Surg 2021 
among the study population (200 subjects, 400 maxillary antra). Among the 200 CBCT scans, 137 scans (274 maxillary antra) were of male subjects, and 63 scans (126 maxillary antra) were of female subjects. The prevalence of LAIC in the maxillary antra of male subjects was $63.1 \%$ (173 maxillary sinuses). The prevalence of LAIC in the maxillary antra of female subjects was $60.3 \%$ (76 maxillary antra). There was no statistically significant difference in prevalence of LAIC between male and female subjects $(P=0.542)$. The mean distance between the LAIC and the alveolar crest in the posterior maxillary teeth is stated in Table 1 . The mean distance between the most inferior point of the alveolar bone and the inferior border of the LAIC in the posterior maxillary region was $19.83 \pm 3.12 \mathrm{~mm}$.

There was a significant difference between maxillary molar and premolar regions in mean distance from the most inferior point of the alveolar bone and the inferior border of the LAIC.(Table 2)

Fifty-three subjects had an edentulous area in the maxillary or mandibular region. Among them, 32 subjects had a subsinusal edentulous area (edentulous area extending anteriorly from the mesial aspect of the maxillary first premolar posteriorly to the distal aspect of the maxillary second molar). Among these 32 subjects, 12 had bilateral sub-sinusal edentulous areas and 20 had a unilateral edentulous area. There was no statistically significant difference in mean distance from the most inferior point of the alveolar bone and the inferior border of the LAIC between dentulous and edentulous areas

Table 1. Distance between the most inferior point of the alveolar bone and the inferior border of the lateral antral intraosseous canal

\begin{tabular}{lc}
\hline \multicolumn{1}{c}{ Area of dentition } & Distance $(\mathrm{mm})$ \\
\hline Maxillary first molar & $16.24 \pm 2.59$ \\
Maxillary second molar & $16.53 \pm 2.71$ \\
Maxillary first premolar & $25.24 \pm 3.65$ \\
Maxillary second premolar & $21.33 \pm 3.54$ \\
\hline
\end{tabular}

Values are presented as mean \pm standard deviation.

Shishir Ram Shetty et al: Cone-beam computed tomography characterization of the intraosseous vascular canal in the lateral wall of the maxillary antrum. J Korean Assoc Oral Maxillofac Surg 2021

Table 2. Comparison of mean distances between maxillary molar and premolar areas

\begin{tabular}{ccc}
\hline Area of dentition & Distance $(\mathrm{mm})$ & $P$-value \\
\hline Maxillary molar area & $16.38 \pm 2.65$ & 0.05 \\
Maxillary premolar area & $23.28 \pm 3.59$ & \\
\hline
\end{tabular}

Values are presented as mean \pm standard deviation.

$P$-value by $t$-test.

Shishir Ram Shetty et al: Cone-beam computed tomography characterization of the intraosseous vascular canal in the lateral wall of the maxillary antrum. J Korean Assoc Oral Maxillofac Surg 2021
$(P=0.1)$. (Table 3)

The LAICs were categorised according to medio-lateral location within the antral wall based on the criteria by Lee et al. ${ }^{13}$.(Fig. 3) In only 3 cases, the canal bulged towards the outer side of the wall (G1-extrasinusal).(Fig. 4. A) Canals were embedded within the wall (G2-intraosseous) (Fig. 4. B) in 70 sinus walls, whereas canals bulged towards the inner side of the wall in 176 sinus walls (G3-intrasinusal).(Fig. 4. C) The diameter of the antral canal was classified based on the criteria devised by Mardinger et al. ${ }^{12}$. The diameter was less than $1 \mathrm{~mm}$ in the majority of cases $(n=113)$. Eighty-three LAICs had a diameter of 1-2 $\mathrm{mm}$, and 53 LAICS had a diameter of 2-3 mm.(Fig. 5)

\section{Discussion}

In the present study, LAIC was detected in $62.3 \%$ of 200 CBCT scans. A similar percentage $(67.1 \%)$ was reported by Rahpeyma et al. ${ }^{7}$, although their study only evaluated 35 CBCT scans. In a Thai study of 184 CBCT scans, the LAIC was detected in $60.3 \%$ of the samples ${ }^{4}$. Higher percentage was reported in recently conducted studies in a Chinese

Table 3. Comparison of mean distances between dentulous and edentulous areas

\begin{tabular}{ccc}
\hline $\begin{array}{c}\text { Dentulous area vs } \\
\text { edentulous area }\end{array}$ & Distance $(\mathrm{mm})$ & $P$-value \\
\hline Dentulous sub-sinusal area & $19.86 \pm 3.10$ & 0.1 \\
Edentulous sub-sinusal area & $19.80 \pm 3.15$ & \\
\hline
\end{tabular}

Values are presented as mean \pm standard deviation.

$P$-value by independent sample $t$-test.

Shishir Ram Shetty et al: Cone-beam computed tomography characterization of the intraosseous vascular canal in the lateral wall of the maxillary antrum. J Korean Assoc Oral Maxillofac Surg 2021

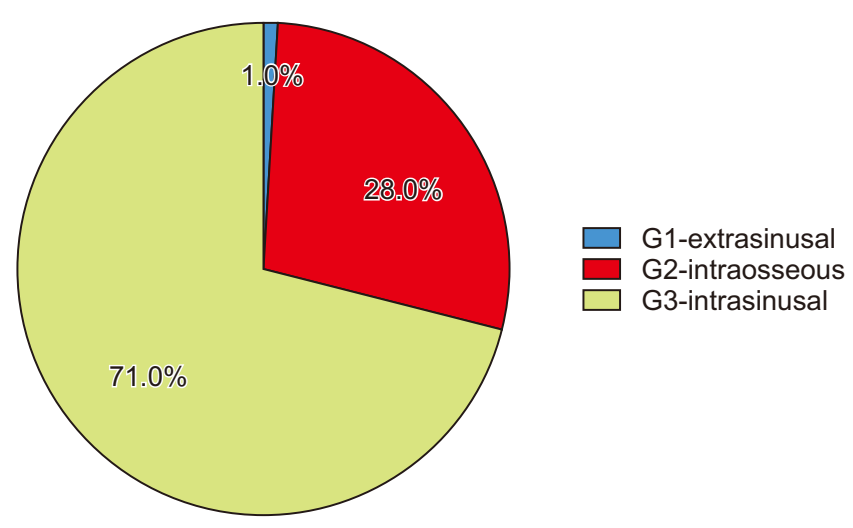

Fig. 3. Categorization of the canals based on the medio-lateral location within the antral wall.

Shishir Ram Shetty et al: Cone-beam computed tomography characterization of the intraosseous vascular canal in the lateral wall of the maxillary antrum. J Korean Assoc Oral Maxillofac Surg 2021 

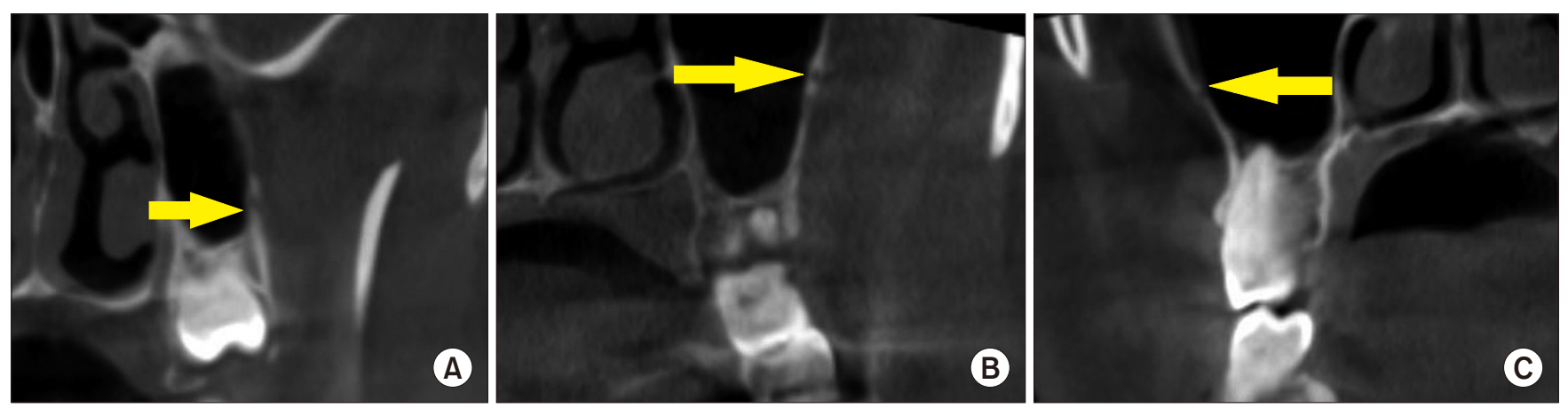

Fig. 4. Tomographic appearance of lateral antral intraosseous canals according to classification of Lee et al. ${ }^{13}$. A. G1-extrasinusal type. B. G2-intraosseous type. C. G3-intrasinusal type.

Shishir Ram Shetty et al: Cone-beam computed tomography characterization of the intraosseous vascular canal in the lateral wall of the maxillary antrum. J Korean Assoc Oral Maxillofac Surg 2021

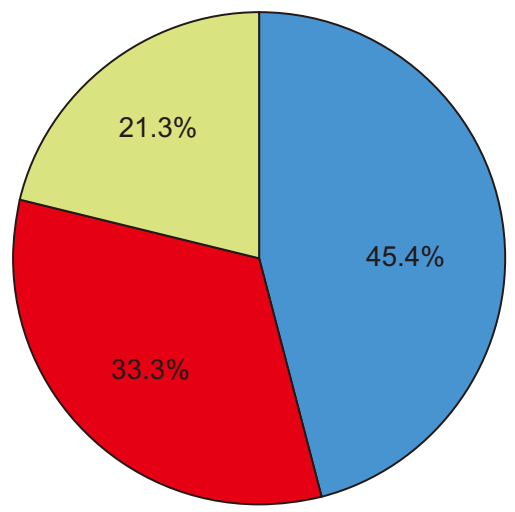

Fig. 5. Categorization of lateral antral intraosseous canals according to diameter of the canals.

Shishir Ram Shetty et al: Cone-beam computed tomography characterization of the intraosseous vascular canal in the lateral wall of the maxillary antrum. J Korean Assoc Oral Maxillofac Surg 2021

population $^{14}(87.6 \%$ of $484 \mathrm{CBCT}$ scans) and a Mexican population $^{15}$ ( $90 \%$ of 1,005 CBCT scans). One of the earliest reported studies ${ }^{12}$ in 2007 demonstrated lateral intraosseous antral canals in $55 \%$ of 208 scans. However, the study was conducted using CT. Another CT based study conducted in 2016 reported presence of intraosseus antral canal in 32\% of the 284 scans that were examined ${ }^{13}$. Generally, CBCTbased studies show a higher percentage and better detection of LAIC than CT-based studies, perhaps because CBCT tends to display a superior spatial resolution compared to fan beam computed tomography ${ }^{16}$. In addition, some researchers have suggested that the higher spatial resolution observed in CBCT is due to the smaller voxel size of the $\operatorname{scan}^{17}$.

On the other hand, the differences in percentages of LAIC could be attributed to racial variations, since these studies were carried out in different parts of the world.

The present study demonstrated no significant difference in prevalence of LAIC between male and female subjects. Simi- lar outcomes were reported by Lee et al. ${ }^{13}$ and Rahpeyma et al. ${ }^{7}$. In one recent CBCT-based study, the occurrence of lateral antral canal walls was higher in males compared to females ${ }^{6}$. The researchers stated that the probability of detection of antral canals increases significantly as thickness of the antral wall increases, which is the probable reason for the increased radiographic detection of antral canals in male subjects in their study. When the location of the canal in the mediolateral aspect of the antral wall was evaluated, we found that $78 \%$ of the canals had an intrasinusal position. Similar radiographic features were reported by Lee et al. ${ }^{13}$. Extrasinusal is the least common location of the canal within the antral wall. However, one Korean study ${ }^{18}$ conducted on cadavers reported that the extrasinusal variety was most common.

When the diameter of LAIC was evaluated, most were less than $1 \mathrm{~mm}$. The diameter of the canals plays a very important role in the radiographic detection of antral canals. LAICs with a diameter less than $0.5 \mathrm{~mm}$ are difficult to detect on routine CBCT scans ${ }^{19}$. Furthermore, the diameter of the LAIC has clinical significance in surgical interventions in the posterior maxillary sinus antrum area as its alerts the surgeon to possible risk of hemorrhage during surgery ${ }^{20}$. The surgeon can adjust the location of the osteotomy window according to pre-surgical CBCT evaluation to avoid complications ${ }^{9}$. Despite a detailed radiographic examination of the surgical site, however, accidental exposure of the antral vessels, which might lead to bleeding, can occur ${ }^{20,21}$. This can be attributed to the heterogeneous pathways of the blood vessels, which can be partially intraosseous or completely extraosseous ${ }^{22}$. Researchers have advised the use of electrocautery or bone wax for management of bleeding subsequent to accidental rupture of these blood vessels ${ }^{22}$. Future CBCT-based research should focus on not only determining the point position of 
the LAIC, but also on tracing its pathways.

\section{Conclusion}

This study established the average measurement for location of the LAIC with reference to maxillary alveolar bone in the UAE, which has not been previously reported. This data will aid the surgeon in avoiding the LAIC during sinus lift procedures and reduce the risk of hemorrhage.

\section{ORCID}

Shishir Ram Shetty, https://orcid.org/0000-0002-8097-6024

Saad Wahby Al Bayatti, https://orcid.org/0000-0002-58152221

Hesham Marei, https://orcid.org/0000-0002-5967-6473

Raghavendra Shetty, https://orcid.org/0000-0003-12097295

Hossam Abdelatty Abdelmagyd, https://orcid.org/00000002-3958-4563

Alexander Maniangat Luke, https://orcid.org/0000-00025885-7694

\section{Authors' Contributions}

S.R.S. participated in data collection and wrote the manuscript. S.W.A.B., H.M., R.S., and H.A.A. participated in the study design and performed the statistical analysis. A.M.L. participated in the study design and coordination and helped to draft the manuscript. All authors read and approved the final manuscript.

\section{Ethics Approval and Consent to Participate}

The study was approved by the Institutional Review Board of Gulf Medical University (No. INT/COD/FR/006-2020), and the written informed consent was obtained from all patients.

\section{Conflict of Interest}

No potential conflict of interest relevant to this article was reported.

\section{References}

1. Albugami RA, Smith S, Hassan MA, Almas K. Trends in implant dentistry: implant systems, complications and barriers in Riyadh, Saudi Arabia. Dent Med Probl 2019;56:223-30. https://doi. org/10.17219/dmp/108659

2. Akeel R. Attitudes of Saudi male patients toward the replacement of teeth. J Prosthet Dent 2003;90:571-7. https://doi.org/10.1016/ j.prosdent.2003.09.007

3. Zijderveld SA, van den Bergh JP, Schulten EA, ten Bruggenkate CM. Anatomical and surgical findings and complications in 100 consecutive maxillary sinus floor elevation procedures. $\mathrm{J}$ Oral Maxillofac Surg 2008;66:1426-38. https://doi.org/10.1016/ j.joms.2008.01.027

4. Mung San Aung C, Panmekiat S, Pimkhaokham A. The study of the alveolar antral artery canal in using cone beam computed tomography. Mahidol Dent J 2017;37:63-9.

5. Elian N, Wallace S, Cho SC, Jalbout ZN, Froum S. Distribution of the maxillary artery as it relates to sinus floor augmentation. Int $\mathrm{J}$ Oral Maxillofac Implants 2005;20:784-7.

6. Varela-Centelles P, Loira M, González-Mosquera A, Romero-Men$\operatorname{dez}$ A, Seoane J, García-Pola MJ, et al. Study of factors influencing preoperative detection of alveolar antral artery by CBCT in sinus floor elevation. Sci Rep 2020;10:10820. https://doi.org/10.1038/ s41598-020-67644-9

7. Rahpeyma A, Khajehahmadi S, Amini P. Alveolar antral artery: does its diameter correlate with maxillary lateral wall thickness in dentate patients? Iran J Otorhinolaryngol 2014;26:163-7.

8. Park WH, Choi SY, Kim CS. Study on the position of the posterior superior alveolar artery in relation to the performance of the maxillary sinus bone graft procedure in a Korean population. J Korean Assoc Oral Maxillofac Surg 2012;38:71-7. https://doi.org/10.5125/ jkaoms.2012.38.2.71

9. Kim JH, Ryu JS, Kim KD, Hwang SH, Moon HS. A radiographic study of the posterior superior alveolar artery. Implant Dent 2011;20:306-10. https://doi.org/10.1097/ID.0b013e31822634bd

10. Güncü GN, Yildirim YD, Wang HL, Tözüm TF. Location of posterior superior alveolar artery and evaluation of maxillary sinus anatomy with computerized tomography: a clinical study. Clin Oral Implants Res 2011;22:1164-7. https://doi.org/10.1111/j.16000501.2010.02071.x

11. Ilgüy D, Ilgüy M, Dolekoglu S, Fisekcioglu E. Evaluation of the posterior superior alveolar artery and the maxillary sinus with CBCT. Braz Oral Res 2013;27:431-7. https://doi.org/10.1590/ S1806-83242013000500007

12. Mardinger O, Abba M, Hirshberg A, Schwartz-Arad D. Prevalence, diameter and course of the maxillary intraosseous vascular canal with relation to sinus augmentation procedure: a radiographic study. Int J Oral Maxillofac Surg 2007;36:735-8. https://doi. org/10.1016/j.ijom.2007.05.005

13. Lee J, Kang N, Moon YM, Pang EK. Radiographic study of the distribution of maxillary intraosseous vascular canal in Koreans. Maxillofac Plast Reconstr Surg 2016;38:1. https://doi.org/10.1186/ s40902-015-0045-X

14. Sun W, Liu A, Gong Y, Shu R, Xie Y. Evaluation of the anastomosis canal in lateral maxillary sinus wall with cone beam computerized tomography: a clinical study. J Oral Implantol 2018;44:5-13. https://doi.org/10.1563/aaid-joi-D-17-00129

15. Cruz ILA, Palacios VDE, Miranda VJE, Cazar AM, Martínez OPA. [CBCT evaluation of the alveolar antral artery in a Mexican cohort and its relationship to maxillary sinus floor lifting]. Rev ADM 2016;73:286-90. Spanish.

16. Lechuga L, Weidlich GA. Cone beam CT vs. fan beam CT: a comparison of image quality and dose delivered between two differing CT imaging modalities. Cureus 2016;8:e778. https://doi. org/10.7759/cureus. 778 
17. Watanabe H, Honda E, Tetsumura A, Kurabayashi T. A comparative study for spatial resolution and subjective image characteristics of a multi-slice CT and a cone-beam CT for dental use. Eur J Radiol 2011;77:397-402. https://doi.org/10.1016/j.ejrad.2009.09.023

18. Hur MS, Kim JK, Hu KS, Bae HE, Park HS, Kim HJ. Clinical implications of the topography and distribution of the posterior superior alveolar artery. J Craniofac Surg 2009;20:551-4. https://doi. org/10.1097/SCS.0b013e31819ba1c1

19. Yoshida S, Kawai T, Asaumi R, Miwa Y, Imura K, Koseki H, et al. Evaluation of the blood and nerve supply patterns in the molar region of the maxillary sinus in Japanese cadavers. Okajimas Folia Anat Jpn 2010;87:129-33. https://doi.org/10.2535/ofaj.87.129

20. Kim J, Jang H. A review of complications of maxillary sinus augmentation and available treatment methods. J Korean Assoc Oral Maxillofac Surg 2019;45:220-4. https://doi.org/10.5125/jkaoms.2019.45.4.220

21. Kim YK, Ku JK. Sinus membrane elevation and implant place- ment. J Korean Assoc Oral Maxillofac Surg 2020;46:292-8. https:// doi.org/10.5125/jkaoms.2020.46.4.292

22. Maridati P, Stoffella E, Speroni S, Cicciu M, Maiorana C. Alveolar antral artery isolation during sinus lift procedure with the double window technique. Open Dent J 2014;8:95-103. https://doi. org/10.2174/1874210601408010095

How to cite this article: Shetty SR, Al Bayatti SW, Marei H, Shetty R, Abdelmagyd HA, Luke AM. Cone-beam computed tomography characterization of the intraosseous vascular canal in the lateral wall of the maxillary antrum. J Korean Assoc Oral Maxillofac Surg 2021;47:34-39. https://doi.org/10.5125/jkaoms.2021.47.1.34 